\title{
Prevalence and risk factors of superficial fungal infections among primary school pupils in llorin, North Central Nigeria
}

\author{
Louis Odeigah, ${ }^{1}$ Stella Rotifa, ${ }^{2}$ Rasaq Shittu, ${ }^{3}$ Yahkub Mutalub ${ }^{4}$ \\ ${ }^{1}$ Department of Family Medicine, Faculty of Clinical Sciences, College of Health Sciences, University of \\ Ilorin, Ilorin, Kwara State; ${ }^{2}$ Department of Epidemiology and Community Health, Federal Medical Center, \\ Yenagua, Bayelsa-State; ${ }^{3}$ Department of Family Medicine, University of Ilorin Teaching Hospital, Ilorin, \\ Kwara-State; ${ }^{4}$ Department of Clinical Pharmacology/Family Medicine, Abubakar Tafawa Balewa \\ University (ATBU)/ATBU Teaching Hospital, Bauchi, Bauchi-State, Nigeria
}

\begin{abstract}
Superficial fungal infections are common in the tropics particularly in the rural areas where children are predisposed. The causative organisms include dermatophytes, yeasts and non-dermatophyte moulds. To determine the prevalence and risk factors of superficial fungal infections among primary school pupils aged 5-
\end{abstract}

Correspondence: Louis Odeigah Department of Family Medicine, Faculty of Clinical Sciences, College of Health Sciences, University of Ilorin, Ilorin, Kwara -State, Nigeria.

Tel: 08069048555

E-mail; lodeigah@yahoo.com

Key words: Superficial fungal infection, risk factors, pupils.

Contributions: LO, conceptualization, literature review, study design, data collection, data analysis, discussion, manuscript writing and final authorization; SR, literature review, study design, data analysis, discussion, manuscript writing and final authorization; RS, literature review, data collection, data analysis, discussion, manuscript writing and final authorization; YM, conceptualization, literature review, study design, data analysis, discussion, manuscript writing and final authorization.

Conflict of interest: The authors declare no conflict of interest.

Funding: None.

Acknowledgement: We are grateful to the Ilorin East Local Government Chairman, Councilors, officials of the Local Education Authority, the Head Teachers and all teachers and pupils of the Primary Schools and Laboratory Scientists at the University of Ilorin Teaching Hospital.

Ethics approval and consent to participate: Approval Number NHREC/01/04/2017 was obtained from University of Ilorin Teaching Hospital, Ilorin Ethical Review Committee for the study. All respondents included in the study consented to participate.

Availability of data and materials: The e-copy of the original data is available on request.

Received for publication: 10 January 2020.

Revision received: 3 June 2020.

Accepted for publication: 3 June 2020.

This work is licensed under a Creative Commons Attribution NonCommercial 4.0 License (CC BY-NC 4.0).

(C) Copyright: the Author(s),2020

Licensee PAGEPress, Italy

Annals of African Medical Research 2020; 3:100

doi:10.4081/aamr.2020.100
16 years in Oke-Oyi, Kwara State. A cross-sectional survey was carried out from April through July 2017 among 602 pupils aged 5-16 years in Oke-Oyi, Ilorin East Local Government Area of Kwara State. Out of the 602 pupils screened during the study, 180 pupils were suspected clinically to have superficial fungal infection and a total of 180 skin specimens were collected from the pupils. The prevalence of clinically suspected fungal infection was $29.9 \%(180 / 602)$, dermatophytes accounted for $16.7 \%(30 / 180)$, while non-dermatophyte moulds accounted for about half of the isolates, $51.7 \%(93 / 180)$. Some of the factors that were significantly associated with the risk of acquisition of dermatophytic infections include age, past history of similar lesions, over-crowding, normal sweat pattern and unkempt socks worn by the pupils among others. This study has shown that superficial fungal infections are common among pupils in Oke-Oyi in Ilorin East Local Government Area of Kwara State and the risk factors include among others, young age, past history of skin infections, overcrowding and unkempt socks worn by pupils. Therefore sociodemographic and behavioural factors influence the occurrence of superficial fungal infections in the study area.

\section{Introduction}

Superficial fungal infections are caused by dermatophytes, yeasts and non-dermatophyte moulds, although dermatophytes are responsible for most of the superficial fungal infections. ${ }^{1}$ The literature has identified several risk factors for fungal infections with predominance of one over the other based on peculiarities of the climate, human activity in the place studied and level of development of the people. ${ }^{2}$

In the tropics, the hot and humid weather predisposes to fungal infections by increased sweating and maceration of the skin. Other predisposing factors include poor socio-economic conditions prevalent in developing countries, ${ }^{3}$ overcrowding, poor hygienic practices and lack of adequate water supply. Studies from Africa put the prevalence of superficial fungal infections in school children at $35.20 \%$ in Tanzania and $40.57 \%$ in Awka in Anambra State, Nigeria. ${ }^{4,5}$ Poor personal hygiene, frequent body contact, poor environmental sanitation, over-crowding and low socio-economic status predispose pupils to fungal infections. ${ }^{6}$ Superficial fungal infections in pupils cause morbidity and lower their quality of life leading to poor school attendance and its various consequences as well anxiety for their parents. ${ }^{7,8}$ This is why this study is important because there is dearth of literature on the prevalence and risk factors for superficial fungal infections among pupils in the study area. The aim of this study was to determine the prevalence of superficial fungal infections and the associated risk factors among 
primary school pupils in Oke-Oyi in Kwara State, so as to provide evidence based preventive measures and thus reducing the prevalence and associated morbidity of superficial fungal infections.

\section{Materials and Methods}

This study was a cross-sectional survey, involving all primary school pupils aged 5 to 16 years in the two public primary schools in Oke-Oyi, a semi urban community in Ilorin East Local Government Area of Kwara State. A multistage random sampling was adopted in selecting the pupils who participated in the study. Stage 1 involved all the pupils in the 2 public primary schools in Oke-Oyi. In the stage 2 of the multistage random sampling, 2 Arms in each class of 4 Arms (A, B, C and D) in Primary One to Primary Six of the two public primary schools were randomly chosen by balloting. In Stage 3, all the pupils in the randomly selected 24 Arms of the primary schools were screened for eligibility and recruited into the study using their Class registers. This study was approved by the Ethics Review Committee of the University of Ilorin Teaching Hospital, Ilorin and consent to carry out the study was obtained from the Local Education Authority. Structured questionnaire was administered to clinically suspected, fungal infected pupils by interview. Those with skin lesions compatible with dermatophytosis had samples taken from the affected parts of the body after parental consent and pupil's verbal assent had been obtained. A portion of the obtained sample after a gentle scraping of the affected skin with a sterile size 11 surgical blade was placed on a clean blotting paper for microscopy and another portion inoculated directly on Sabouraud Dextrose Agar (SDA) for mycological examination using conventional technique.

All samples collected in the field were transferred to the Microbiology Laboratory of the University of Ilorin Teaching Hospital, Ilorin, where it was cultured and subjected to microscopy using 10\% KOH (Potassium Hydroxide) and Sabouraud Dextrose Agar (SDA). The media were incubated at room temperature and at $37^{\circ} \mathrm{C}$ for a minimum period of three weeks. Positive cultures were examined macroscopically and microscopically for species identification. All data collected from the participants were entered into a database created specifically for this study using Epi-Info $6.04 \mathrm{~d}$. All data were kept confidential at all stages of the study. A p-value less than 0.05 was taken as statistically significant.

\section{Results}

A total of 602 primary school pupils (398 males and 204 females) were screened, giving a male to female ratio of $2: 1$. One hundred and eighty respondents (123 males and 57 females) were suspected to have superficial fungal infection clinically. The overall mean age of the respondents was $8.99 \pm 2.97$ years.

Table 1, shows that the male sex was more infected clinically with dermatophytes than their female counterpart. The 9-12 years age-group was the most infected age-group with dermatophytes.

The prevalence of clinically suspected fungal infection was $29.9 \%$ (180/602), all of which were positive for hyphae on $\mathrm{KOH}$ microscopy, however $68.3 \%$ (123/180) were confirmed with SDA culture (Table 2). Dermatophytes accounted for $16.7 \%(30 / 180)$ while non-dermatophyte moulds accounted for $51.7 \%(93 / 180)$ of the isolates.

Out of the 180 pupils suspected to have dermatophytic infection clinically, $52(28.9 \%)$ of the cases had a similar lesion in the past. The duration of the former lesion before it disappeared was unknown to majority of the $29(16.1 \%)$ respondents. Seventy four $(41.1 \%)$ of the respondents said their current skin lesion started $\leq 3$ months before the onset of the study.

A family history of infection was found in 70 (38.9\%) of the clinically suspected cases. In 48 (26.7\%) cases, blood brothers of the respondents were the family members that had a similar skin lesion. However, in $4(2.3 \%)$ cases, their family members with similar lesions were adults.

Less than half of the 70 respondents with a family history of infection, 34(18.9\%) said that their family members with a similar skin lesion were on one form of treatment or the other, but most of the respondents did not know the length of time for which they had been on treatment.

A habit of sharing materials was common among respondents. In $129(71.7 \%)$ of the pupils, the hair comb or head brush was shared, while multiple materials including clothings were shared in the great majority. A total of $131(72.8 \%)$ respondents had a history of profuse sweating during such episodes, 53 (40.5\%) of the pupils did nothing to their sweat, while the rest pupils either changed their soaked clothes $33(18.3 \%)$ or took a bath $45(25.0 \%)$ and this opportunity was available to those from average homes with adequate supply of water.

A greater proportion of the respondents 119 (66.1\%) reported not using socks. Of the remaining $61(33.9 \%)$ pupils $11(6.1 \%)$ noticed that their socks often smelt awful and another $50(27.8 \%)$ denied such. In nearly all of the cases, the frequency of changing socks was 3 times per week or less 54 (30.0\%). Different traditional treatments were being employed for the skin lesions in the community (Figure 1). Comparison of reported use of these medicaments previously and currently showed that there had been a considerable reduction in the use of these medicaments for present skin lesions.

The risk factors associated with fungal infections in the respondents among others include age, especially the age group 912 years as shown in Table 3 , as this was statistically significant $(p=0.008)$. The male pupils had more cases of positive fungal infection than their female counterparts, but the difference was not statistically significant $(\mathrm{p}=0.409)$.

The presence of a previous similar lesion in the respondents was significantly associated with acquisition of fungal infection $(p=0.004)$, whereas, the same cannot be said for similar lesions in a family member $(\mathrm{p}=0.903)$. The grater the number of persons living in the same room, the greater was the likelihood of acquisition

Table 1. Demographic characteristics of respondents suspected to have dermatophytoses clinically.

\begin{tabular}{lccc}
$\begin{array}{l}\text { Age groups } \\
\text { (years) }\end{array}$ & Male (123) & Female $(57)$ & Total (N=180) \\
n (\%) \\
$5-8$ & 61 & 20 & $81(45.0)$ \\
$5-8$ & 45 & 27 & $72(40.0)$ \\
\hline $13-16$ & 17 & 10 & $27(15.0)$ \\
\hline
\end{tabular}

Table 2. Sex distribution of respondents who were positive for fungi on culture with Sabouraud Dextrose Agar.

\begin{tabular}{lccc} 
Type of fungi & \multicolumn{2}{c}{ Sex } & Total \\
& Male (123) & Female (57) & $(\mathrm{N}=123)$ \\
Dermatophyte (D) & 19 & 11 & $30(16.7)$ \\
Non-Dermatophyte(ND) & 67 & 26 & $93(51.7)$ \\
\hline Total & 86 & 37 & $23(68.3)$ \\
\hline
\end{tabular}


of fungal infection $(\mathrm{p}=0.054)$. The sharing of materials among respondents' households did not seem to increase the likelihood of acquiring fungal infection ( $\mathrm{p}=0.765)$.

Those who reported that they did not sweat excessively were more at risk of infection by dermatophytes. The use of socks and the cleanliness of it, was associated with an increased risk of acquisition of fungal infections as also the practice of barbing at the local barber shop. In addition, the poor personal hygiene of the

Table 3. Risk factors associated with fungal infection in respondents.

\begin{tabular}{|c|c|c|c|c|}
\hline $\begin{array}{l}\text { Variables } \\
\text { Positive }\end{array}$ & $\begin{array}{l}\text { Negative } \\
(\mathrm{n}=109)\end{array}$ & $\begin{array}{l}(\mathrm{N}=180) \\
(\mathrm{n}=71)\end{array}$ & Total & $\mathrm{X}^{2}, \mathrm{p}$-value \\
\hline $\begin{array}{l}\text { Age groups (in years) } \\
5-8 \\
9-12 \\
13-16\end{array}$ & $\begin{array}{l}39 \\
52 \\
18\end{array}$ & $\begin{array}{c}42 \\
20 \\
9\end{array}$ & $\begin{array}{l}81 \\
72 \\
27\end{array}$ & $X^{2}=9.75,0.008$ \\
\hline $\begin{array}{l}\text { Sex } \\
\text { Male } \\
\text { Female }\end{array}$ & $\begin{array}{l}77 \\
32\end{array}$ & $\begin{array}{l}46 \\
25\end{array}$ & $\begin{array}{l}123 \\
57\end{array}$ & $X^{2}=0.68,0.409$ \\
\hline $\begin{array}{l}\text { Past similar lesion } \\
\text { Yes } \\
\text { No }\end{array}$ & $\begin{array}{l}40 \\
69\end{array}$ & $\begin{array}{l}12 \\
59\end{array}$ & $\begin{array}{c}52 \\
128\end{array}$ & $X^{2}=8.20,0.004$ \\
\hline $\begin{array}{l}\text { Similar lesion in family m } \\
\text { Yes } \\
\text { No }\end{array}$ & $\begin{array}{l}42 \\
67\end{array}$ & $\begin{array}{l}28 \\
43 \\
\end{array}$ & $\begin{array}{c}70 \\
110\end{array}$ & $X^{2}=0.01,0.903$ \\
\hline $\begin{array}{l}\text { No living in same room } \\
\quad \leq 2 \\
\geq 2\end{array}$ & $\begin{array}{l}15 \\
94\end{array}$ & $\begin{array}{l}20 \\
51\end{array}$ & $\begin{array}{c}35 \\
145\end{array}$ & $X^{2}=5.70,0.017$ \\
\hline $\begin{array}{l}\text { Sharing materials } \\
\text { Yes } \\
\text { No }\end{array}$ & $\begin{array}{l}79 \\
30\end{array}$ & $\begin{array}{l}50 \\
21\end{array}$ & $\begin{array}{l}129 \\
51\end{array}$ & $X^{2}=0.09,0.765$ \\
\hline $\begin{array}{l}\text { Frequency of baths } \\
\text { 1-2 times/week } \\
\text { 3-4 times/week } \\
\text { Daily }\end{array}$ & $\begin{array}{l}2 \\
45 \\
62\end{array}$ & $\begin{array}{c}2 \\
31 \\
38\end{array}$ & $\begin{array}{c}4 \\
76 \\
100\end{array}$ & $X^{2}=0.33,0.847$ \\
\hline $\begin{array}{l}\text { Sweating profusely } \\
\text { Yes } \\
\text { No }\end{array}$ & $\begin{array}{l}68 \\
41\end{array}$ & $\begin{array}{c}63 \\
8\end{array}$ & $\begin{array}{c}131 \\
49\end{array}$ & $X^{2}=15.06,0.001$ \\
\hline $\begin{array}{l}\text { Socks smelling badly } \\
\text { Yes } \\
\text { No }\end{array}$ & $\begin{array}{l}10 \\
40\end{array}$ & $\begin{array}{c}1 \\
10\end{array}$ & $\begin{array}{l}11 \\
50\end{array}$ & $X^{2}=18.16,0.001$ \\
\hline $\begin{array}{l}\text { Don't use } \\
\text { Place of barbing hair } \\
\text { Local barber } \\
\text { Hair saloon } \\
\text { Personal clipper }\end{array}$ & $\begin{array}{c}59 \\
39 \\
58 \\
2\end{array}$ & $\begin{array}{c}60 \\
12 \\
54 \\
0\end{array}$ & $\begin{array}{c}119 \\
\\
51 \\
112 \\
2\end{array}$ & $X^{2}=10.25,0.006$ \\
\hline $\begin{array}{l}\text { Personal hygiene } \\
\text { Hygienic } \\
\text { Unhygienic }\end{array}$ & $\begin{array}{l}50 \\
59\end{array}$ & $\begin{array}{l}47 \\
24\end{array}$ & $\begin{array}{l}97 \\
83\end{array}$ & $X^{2}=7.15,0.008$ \\
\hline $\begin{array}{l}\text { Swam in communal bath } \\
\text { Yes } \\
\text { No }\end{array}$ & $\begin{array}{l}36 \\
73\end{array}$ & $\begin{array}{c}6 \\
65\end{array}$ & $\begin{array}{c}42 \\
138 \\
\end{array}$ & $X^{2}=14.52,0.000$ \\
\hline $\begin{array}{l}\text { Type of sports } \\
\text { Swimming } \\
\text { Athletics } \\
\text { Football }\end{array}$ & $\begin{array}{c}8 \\
26 \\
54\end{array}$ & $\begin{array}{c}2 \\
34 \\
26\end{array}$ & $\begin{array}{l}10 \\
60 \\
80\end{array}$ & $X^{2}=10.27, * 0.006$ \\
\hline $\begin{array}{l}\text { Keeping of pets } \\
\text { Yes } \\
\text { No }\end{array}$ & $\begin{array}{l}87 \\
22\end{array}$ & $\begin{array}{c}64 \\
7 \\
\end{array}$ & $\begin{array}{l}151 \\
29 \\
\end{array}$ & $\mathrm{X}^{2}=3.39,0.066$ \\
\hline $\begin{array}{l}\text { Type of pets kept } \\
\text { Cat } \\
\text { Dog } \\
\text { Cat }+ \text { dog } \\
\text { Birds }+ \text { goat }\end{array}$ & $\begin{array}{c}2 \\
9 \\
14 \\
62\end{array}$ & $\begin{array}{c}0 \\
3 \\
2 \\
59\end{array}$ & $\begin{array}{c}2 \\
12 \\
16 \\
121\end{array}$ & $X^{2}=10.82, * 0.012$ \\
\hline $\begin{array}{l}\text { Playing with pets } \\
\text { Yes } \\
\text { No }\end{array}$ & $\begin{array}{l}19 \\
90\end{array}$ & $\begin{array}{c}4 \\
67\end{array}$ & $\begin{array}{c}23 \\
157\end{array}$ & $\mathrm{X} 2=5.37, * 0.020$ \\
\hline
\end{tabular}

$\mathrm{n}=$ frequency of respondents in observations, $\mathrm{N}=$ total number of clinically suspected cases. 
respondents was associated with an increased risk of acquisition of fungal infections. Swimming in the communal bath was also associated with an increased risk of acquiring fungal infections. Similarly, when the individual participated in swimming as a sport, the risk was further increased.

Though the proportion of those that kept pets had more cases of positive fungal elements on $\mathrm{KOH}$ examination, it was those who had no pets that had an increased risk of acquiring fungal infections, though this was not statistically significant.

\section{Discussion and Conclusions}

Knowledge of risk factors for fungal infections is important in its control. Risk factors known to predispose to fungal infections were computed as independent variables in this study.

Age as opposed to gender was a significant risk factor for acquiring fungal infections. This is similar to the findings in Egypt where older age was found to significantly influence acquisition of dermatophytosis. ${ }^{9}$ The 9-12 year age group may be more predisposed because children in this age-group might be expected to personally clean themselves compared to the 5-8 years old who rely more on their parents or elderly persons to clean or bath them, while the 13-16 year age group may be expected to become more aware of themselves and their cleanliness and thus personally cleaning themselves properly. In addition, the 9-12 year age group may be predisposed to fungal dermatosis because they shared materials that otherwise should be personal, such as their combs, head brushes, clothes, hats and caps, in spite of the fact that the sharing of these materials was not found to be significantly related to infection by dermatophytes.

Previous fungal lesions in the respondents as compared to similar lesions in a family member, was a significant risk factor for the acquisition of fungal infection. This finding suggests that previous lesions were not cured by the treatment employed or they had new infection on previous sites. This is against the backdrop that some of the respondents had used traditional medicaments for their past fungal lesions and also had attempted doing the same with the current lesions.

Dermatophytic infections were also linked to overcrowd-

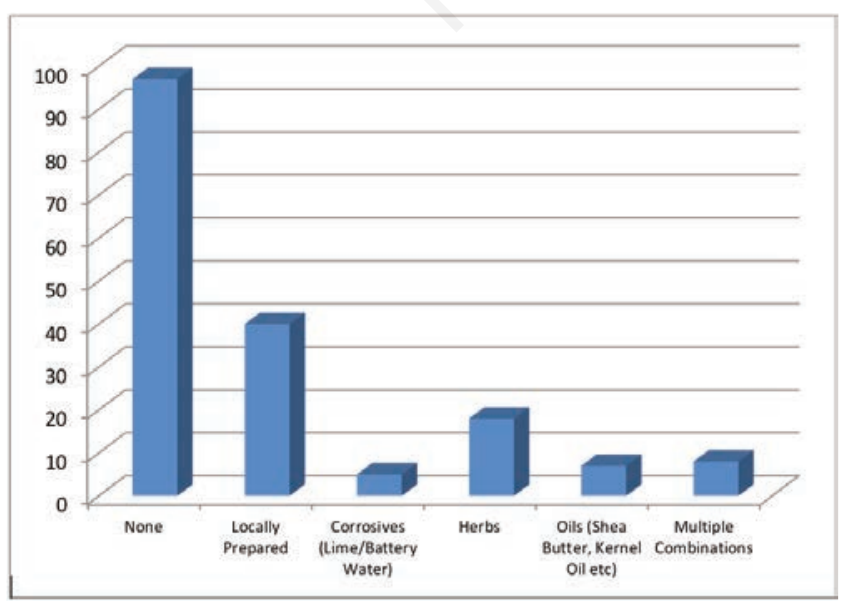

Figure 1. Traditional treatments employed for skin lesions by the pupils. ing. ${ }^{10,11}$ The pupils of the community primary schools surveyed were characterized by families with 3 or more members. This link between crowded living conditions and the increased prevalence of dermatophytic infections has been observed by researchers who noticed that Tinea capitis was commoner in school children from families with 3 or more members sharing a room. ${ }^{11,12}$ In addition, the association of dermatophytic infections with overcrowding probably stems from the likelihood of the sharing of personal materials like towels, combs or hats, among others, which was a common finding in this study, although it was not statistically significant. 9,13

An unkempt pair of socks presented an increased risk of acquisition of fungal infection in the study. This is against the backdrop that only $11.5 \%$ of those who used socks changed them on a daily basis. The remaining pupils changed socks from thrice weekly to a month. This is an additional evidence to support the state of poor personal hygiene of the pupils surveyed.

The place of barbing also presented an increased risk in our study, as noted in previous studies. ${ }^{10}$ Those who patronized local barbers were significantly infected compared with those who barbed at the saloon or used their personal clippers. ${ }^{11}$ This may account for the higher prevalence of Tinea capitis in the study and may explain the higher prevalence in boys. ${ }^{12}$

The frequency and severity of dermatophytic infections have been linked to personal cleanliness. Since $71.1 \%$ of cases of unhygienic children as at the time of clinical examination had positive microscopy compared to $52.5 \%$ of hygienic children, it appeared that unclean children were predisposed to dermatophytic infection and also served as agents of transmission.

In $44 \%$ of the pupils, the bath frequency was $\leq 3-4$ times per week. In the same manner, the respondents did nothing when they were sweating $53(29.4 \%)$ and only $7 / 61$ (3.9\%) of those who used socks changed them on a daily basis. The link between poor personal hygiene and increased prevalence of dermatophyte infections and other parasitic infestations have been confirmed in several studies. $3,10,11,14$

Swimming in communal baths as well as swimming as a form of sporting activity is statistically associated with the increased risk of acquiring fungal infection. In addition, there was a significant risk of dermatophytosis in both swimmers and non-swimmers who used the swimming pool.

Dermatophyte infection can also be acquired directly by transmission through fomites such as upholstery, hair brushes and combs. In spite of the fact that sharing of materials like combs, hair brushes, clothing and hats/caps was not statistically significant for acquisition of fungal infection in this study, there was a high proportion of sharing of materials in the community surveyed.

Contact with animals is considered a risk factor for dermatophytosis. ${ }^{9,13}$ This study found a high level of contact with animals in $151(83.9 \%)$ of the clinically suspected cases. There was evidence of contact with dogs, cats, goats and birds. Given that Tricophyton mentagrophyte (the commonest isolate in this study) can be both anthrophilic and zoophilic in its origin, the frequency of animal to human contact is suggested to be part of the likely means of transmission of the infection among our respondents.

Taking into consideration the risk factors identified in this study, which were mainly patient factors such as personal cleanliness and environmental hygiene, a focused health education was conducted among the pupils surveyed.

Because teachers are important in identifying pupils with skin infection and encouraging them to seek proper treatment, they were given health education on how to recognize pupils with skin infection and to inform parents and guardians appropriately. ${ }^{4}$ 
In conclusion, the study has shown that superficial fungal infections are common among pupils in the study area and the risk factors remain high. Health education, provision of social amenities and improvement in the socio-economic status of the parents are necessary in the prevention and control of superficial fungal infections among the pupils.

\section{References}

1. Prawer S, Bershow A. Superficial Fungal Infections in Clinical Dermatology, 1st ed. McGraw Hill Education; 2013, p.71.

2. Kalu EI, Wagbatsoma V, Ogbaini-Emovon E, et al. Age and sex prevalence of infectious dermatosis among primary school children in a rural South-Eastern community. Pan Afr Med J 2015;20:182.

3. Ayorinde AF, Adesanya OO, Alaran OA. A microbiological study of dermatophyte infections among primary school children in Mowe, Ogun State Nigeria. Res J Biol Sci 2013;5:2059.

4. Chikoi R, Nyawale HA, Mghanga FP. Magnitude and associated risk factors of superficial skin fungal Infections among primary school children in Southern Tanzania. Cureus 2018;10:e 2993. DOI 10.7759/Cureus.2993.

5. Ogbu CC, Okwelogu IS, Umeh AC. Prevalence of superficial fungal Infections among primary school pupils in Awka South. J Mycol Res 2015;2:15-22.

6. Nweze EI, Eke IE. Dermatophytes and dermatophytosis in the
Eastern and Southern parts of Africa. Med Mycol 2018;56:1328.

7. Oke OO, Onayemi O, Olasode OA, et al. The Prevalence and Pattern of Superficial Fungal Infections among school children in Ile-Ife, South Western Nigeria. Dermatol Res Pract 2014;2014:842817. doi.org/10.1155/2014/842917.

8. Ilkit MI, Durdu M. Tenia pedis: the aetiology and global epidemiology of a common fungal Infection. Crit Rev Microbiol 2015;41:374-88. doi:10.3109/1040841X.2013.856853.

9. Bassyouni RH, El-Sheribiny NA, Abd El Raheem TA, Mohammed BH. Changing Epidemiology of Tinea capitis among school children in Egypt. Ann Dermatol 2017;29:13-9.

10. Olutoyin OO, Onayemi O, Gabriel AO. Risk factors associated with acquiring superficial fungal infections in school children in South Western Nigeria: a comparative study. Afr Health Sci 2017; 17:22-30.

11. Akinboro AO, Olasode OA, Onayemi O. The Pattern, risk factors and clinic-aetiological Correlate of Tinea capitis among the children in a tropical community setting of Osogbo, South West Nigeria. Afro-Egypt J Infect Endem Dis 2011;1:53-64.

12. Qadim HH, Golforoushan F, Azimi H, Goldust M. Factors leading to dermatophytosis. Ann Parasitol 2013;59:99-102.

13. Gupta AK, Macleod MA, Foley KA, et al. Fungal skin infections. Paediatr Rev 2017;38:8-22.

14. Bakare OE, Adeyeba OA. Survey of Intestinal Schistosomiasis and soil transmitted helminthes among pupils in Ifelodun, Kwara-State, Nigeria. J Bio Innov 2017;6:79-90. 